$$
\mathrm{d} P_{\mathrm{NO}_{2}} / \mathrm{d} t=\frac{k_{2} k_{3} \cdot P_{\mathrm{H}_{2} \mathrm{O}_{2}{ }^{2}}}{\Sigma k_{5}, M \cdot P_{M}}
$$

This is in good agreement with the experimental equation (I) apart from the order with respect to $\mathrm{H}_{2} \mathrm{O}_{2}$. The most probable causes of this discrepancy are either that the long-chain assumption is not valid, or that $\mathrm{H}_{2} \mathrm{O}_{2}$ is an efficient third body in reaction (5) relative to nitrogen. At present there is no evidence to suggest a choice between the alternative initiation reactions.

The reaction scheme does not account for the pressure decrease observed unless nitrous acid can accumulate at this temperature, which is improbable on thermodynamic grounds ${ }^{6}$. It is more likely that the decrease is due to the establishment of a stationary concentration of nitric acid, since this decomposes slowly at $300^{\circ} \mathrm{C} .{ }^{7}$, and could be formed in the system. Equation (I) does not apply to the variation of the rate within a single run. This effect has not been examined in detail, but it is probably due to secondary reactions caused by the products. In particular, it has been found that $\mathrm{H}_{2} \mathrm{O}_{2}$ and $\mathrm{NO}_{2}$ react at both $70^{\circ}$ and $299^{\circ}$ C., and at the lower temperature this reaction, followed by changes in $P_{N O}$, and total pressure, conforms to the equation:

$$
2 \mathrm{NO}_{2}+\mathrm{H}_{2} \mathrm{O}_{2} \rightarrow 2 \mathrm{HNO}_{3}
$$

It is intended to investigate further both the reaction with $\mathrm{NO}$ and with $\mathrm{NO}_{2}$.

I wish to thank Dr. P. G. Ashmore for many helpful discussions during the course of this work, and Laporte Chemicals, Ltd., for a gift of hydrogen peroxide.

Department of Physical Chemistry,

$$
\text { B. J. Tyler }
$$

1 Tyler, B. J., Ph.D. thesis, Univ. Cambridge (1961).

${ }^{2}$ Ashmore, P. G., and Tyler, B. J., Trans. Farad. Soc., 58, 1108 (1962)

${ }^{3}$ Hoare, D. E., Protheroe, J. B., and Walsh, A. D., Trans. Farad. Soc., 55, 548 (1959).

- Ashmore, P. G., and Levitt, B. P., Seventh Intern. Symp. Combustion, 45 (Combustion Institute, 1958).

s Tyler, B. J., J. Sci. Instrum., 39, 111 (1962).

-Ashmore, P. G., and Tyler, B. J., J. Chem. Soc., 1017 (1961). 'Johnston, H. S., Foering, L., Tao, Y., and Messerly, G. H., J. Amer.
Chem. Soc., 78, 2319 (1951).

\title{
Bromination of Triphenyl Phosphine Borine
}

IN most compounds containing hydrogen linked to boron, the hydrogen atoms have a more or less pronounced electronegative or hydridic character. This is evident in the mildness of the conditions required for their reaction with water or hydrogen chloride to give molecular hydrogen. In the phosphinoborine ring polymers, however, the $\mathbf{B H}_{2}$ groups are exceptionally inert towards hydrolysis. Burg et al. have attributed this to a diminution in the hydridic character of the hydrogen atoms, caused by partial utilization of the $\mathbf{B}-\mathbf{H}$ bonding electrons in forming $\pi$ bonds between the boron and phosphorus atoms ${ }^{1-8}$. Triphenyl phosphine borine, $\left(\mathrm{C}_{6} \mathrm{H}_{5}\right)_{3} \mathrm{P} \cdot \mathrm{BH}_{3}$, is another unusually inert boron hydride derivative. Since our preliminary report that it resisted hydrolysis ${ }^{4}$, we have found that it is not affected by refluxing for $1 \mathrm{hr}$. with $6 N$ hydrochloric acid; nor, when dissolved in benzene, does it react with hydrogen ehloride gas at room temperature. This stable (m.p. $188^{\circ}$ ) and easily prepared compound appeals to us as a material with which to investigate the chemical behaviour of

deactivated hydrogen atoms attached to boron. We here report the first of a series of experiments by means of which we hope to characterize more fully the type of reactivity possessed by these hydrogen atoms.

Triphenyl phosphine borine was first made by passing diborane into a benzene solution of triphenyl phosphine. Using high-vacuum apparatus, bromine was distilled into a suspension of the triphenyl phos. phine borine in dry carbon disulphide. Reaction occurred smoothly at $-40^{\circ}$ according to the equation:

$$
\left(\mathrm{C}_{6} \mathrm{H}_{6}\right)_{3} \mathrm{P} \cdot \mathrm{BH}_{3}+3 \mathrm{Br}_{2} \rightarrow 3 \mathrm{HBr}+\left(\mathrm{C}_{6} \mathrm{H}_{5}\right)_{3} \mathrm{P} . \mathrm{BBr}_{3}
$$

The second reaction product was identified by comparison with a specimen of the triphenyl phosphineboron tribromide complex prepared by mixing the components in carbon disulphide solution. The two substances gave: (a) indistinguishable infra-red spectra (potassium bromide disk method); $(b)$ agreeing melting points (reaction product $212^{\circ}-214^{\circ}$, $\left(\mathrm{C}_{6} \mathrm{H}_{5}\right)_{3} \mathrm{P} . \mathrm{BBr}_{3} 215^{\circ}-217^{\circ}$, mixed m.p. $\left.214^{\circ}\right) ;(c)$ the same hydrolysis products, when refluxed for an hour with carbon tetrachloride and water.

Table 1

\begin{tabular}{ccccc}
\multicolumn{2}{c}{ Reactants } & $\mathrm{HBr}$ formed *, $\dagger$ & \multicolumn{2}{c}{ From hydrolysis of invola- } \\
tile reaction & product \\
$\left(\mathrm{C}_{8} \mathrm{H}_{5}\right)_{3}$ P. $\mathrm{BH}_{3}$ & $\mathrm{Br}_{2}$ & & $\mathrm{H}_{3} \mathrm{BO}_{3}$ & $\mathrm{BHr} \dagger$ \\
0.855 & $2 \cdot 56$ & 2.54 & 0.85 & 2.57 \\
0.873 & $2 \cdot 62$ & $\mathbf{2 . 5 9}$ & 0.87 & 2.64
\end{tabular}
All quantities in m.moles. Reaction in $1.5 \mathrm{ml}$. of carbon disulphide at $-40^{\circ}$.

* Pumped off from reaction mixture at room temperature.

t Determined both gravimetrically as silver bromide and acidietrically.

† The hydrolysis also gave rise to triphenyl phosphine oxide, which was not determined quantitatively. This presumably arose from atmospheric oxidation of the triphenyl phosphine first formed; it was an tribromide adduct were refluxed under the same conditions.

Table 1 shows the practically quantitative stoichiometry of the reaction.

Taken in conjunction with the known lack of hydridic reactivity of the borine hydrogens in this compound, the reaction with bromine may well imply protonic ionization of the borine hydrogens, leading to their replacement by bromine in an $S_{E} 1$ process. But more experiments are needed before alternative mechanisms, such as fission of the $\mathrm{P}-\mathrm{B}$ bond by bromine and its subsequent re-formation, can be ruled out.

H. G. HEAL

I. O. MADDEN

Department of Chemistry,

Queen's University of Belfast.

${ }^{1}$ Burg, A. B., and Wagner, R. I., J. Amer. Chem. Soc., 75, 3872 (1953). ${ }^{2}$ Burg, A. B, and Brendel, G., J. Amer. Chem. Soc., 80, 3198 (1958). ${ }^{3}$ Burg, A. B., Inorganic Polymers, 26 (Chem. Soc. Spec. Pub. No. 15, 1961).

4 Heal, H. G., J. Inorg. Nuclear Chem., 16, 208 (1961).

\section{Reaction of Phenols with Peroxy Radicals}

Although it has been known for a long time that phenols inhibit the autoxidation of many organic substances, the exact nature of the inhibition process is still not completely understood ${ }^{2}$. Most experimental evidence suggests that the reaction involves a straightforward abstraction of the phenolic hydrogen by the substrate peroxy radicals to give a hydroperoxide and a comparatively unreactive phenoxy radical:

$$
R \mathrm{OO}+\varphi \mathrm{OH} \rightarrow \mathrm{ROOH}+\varphi \mathrm{O} .
$$

However, several workers have shown that replacement of the phenolic hydrogen by deuterium has 